\title{
Microhardness Assessment of Two Nanohybrid Composite Resins with Two Curing Technologies
}

\author{
Ebaa Ibrahim Alagha**, Mustafa Ibrahim Alagha ${ }^{2}$ \\ ${ }^{1}$ Department of Restorative Dentistry, Al-Farabi Private Colleges, Faculty of Dentistry, Jeddah, Saudi Arabia; ${ }^{2}$ Department of \\ Restorative Dentistry, School of Dentistry, University of Liverpool, Liverpool, United Kingdom
}

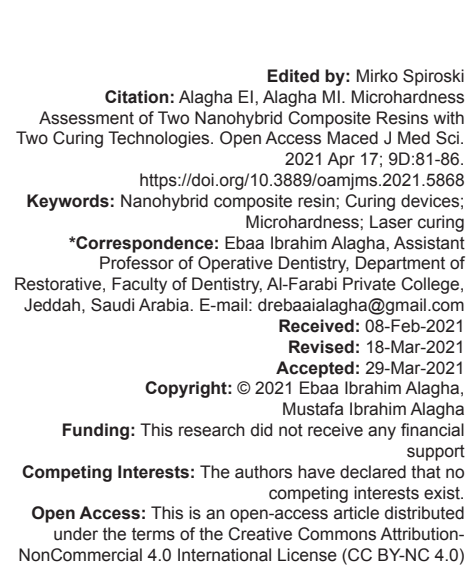

\section{Introduction}

Composite resin restorations have become the material of choice [1] because of their aesthetics', biocompatibility, and adhesive properties [2]. Many methods have been proposed to improve its polymer matrix and manipulation techniques [3]. Composite resins were launched in the dental market, the so called bulk fill composites. This new composite resin can be inserted in $4 \mathrm{~mm}$ bulk placement instead of the current incremental placement technique with low polymerization stresses and high reactivity to the light cure [4]. Proper curing of composite resin restorations is an effective factor that influences the good physical and mechanical properties and biocompatibility of the material [5]. There are four main types of light curing units; quartz-tungsten-halogen (QTH), light-emitting diode (LED), plasma arc (PAC), and laser based units [6]. Dentists should carefully select the curing light source as it literally influences the success of photo-cured restorations [7]. Microhardness evaluation is a reliable technique that determines the depth of cure and it has a clinical aspect of composite curing [8], [9]. The study compared the influence of laser and LED curing units on the microhardness of bulk fill composite resin and nanohybrid universal composite resin.

\section{Materials and Methods}

A total of 120 cylindrical specimens were prepared and divided into two groups (60 each) according to the type of composite resin used. Group A: Bulk Fill composite resin (Tetric EvoCeram, Ivoclar Vivadent, USA) and Group B: Nanohybrid universal composite resin (Mosaic, Ultradent, USA). Each group was subdivided into four subgroups (15 each) according to the different curing technique; Subgroup 1: Subjected to $10 \mathrm{~s}$ of laser curing, Subgroup 2: Subjected to $15 \mathrm{~s}$ of laser curing, Subgroup 3: Subjected to $20 \mathrm{~s}$ of laser curing, and Subgroup 4: Subjected to LED curing for $20 \mathrm{~s}$ Microhardness test 
was done for all specimens on both top and bottom surfaces [5]. The size of the specimen was $4 \mathrm{~mm}$ diameter $\times 6 \mathrm{~mm}$ thickness and prepared in a Teflon split mold. The mold was made of circular Teflon disk milled with specific dimensions (30 $\mathrm{mm}$ diameter and $6 \mathrm{~mm}$ thickness), three cylindrical holes were drilled vertically in the mold, aligned with the longest diameter of the disk and finally the disk horizontally splitted through the diameters of the aligned holes to make the mold symmetrical. The two halves of the mold were assembled with copper ring having a diameter of $35 \mathrm{~mm}$ and a $3 \mathrm{~mm}$ thickness. Mylar strip was placed on a glass slab and the Teflon mold was placed over it. The composite resin material was packed inside the mold. Another Mylar strip was placed over the composite resin and another glass slide was slightly compressed to extrude excess material and to keep the distance between the curing tip and the mold was fixed at $5 \mathrm{~mm}$. Tetric EvoCeram Bulk fill was packed in two increments (to $2 \mathrm{~mm}$ height mark from the bottom and curing, then to the top part of the mold surface) that the thickness of each step does not exceed more than $4 \mathrm{~mm}$ in thickness. Mosaic resin composite was packed into the mold in $2 \mathrm{~mm}$ thickness increments from the bottom of the mold to the top with curing each increment. The composite resin packed and adapted into the mold using Teflon plated non-stick composite placement instrument. Two types of curing systems were used: LED light curing, (BlueLEX LD-105, Monitex, Taiwan) with $2000 \mathrm{mw} / \mathrm{cm}^{2}$ was used according to the manufacturer instructions for $20 \mathrm{~s}$ and laser system, (SIROLaser Blue laser, Sirona, Germany) with wavelength $445 \mathrm{~nm}$ and $500 \mathrm{mw} / \mathrm{cm}^{2}$. The light tip was in direct contact with the glass slap on the top surface of the glass slap over the mold through the different time intervals (10 s., $15 \mathrm{~s}$. , and 20 s.). After photo activation, the mold dissembled and the top and bottom surfaces of each specimen (Figure 1) were finished and polished using superfine bur (SF30 $\mu$, Mani diamond burs, China) and rubber polishing cup then stored in dry incubator at $24^{\circ} \mathrm{C}$ for $24 \mathrm{~h}$ before testing [9]. Vickers hardness number (VHN) was determined on the top and the bottom surfaces for each specimen using a microhardness testing machine (HV-1000DT, Shanghai Daheng Optics and Fine Mechanics Co, Ltd) equipped with a diamond pyramidal microindentor to apply a load of $300 \mathrm{~g}$ for $15 \mathrm{~s}$ [10] at room temperature. The VHN for each surface was recorded and was taken as an average of the three readings. Each specimen was positioned underneath the indenter of the microhardness tester to determine the mean Vickers hardness number (VHN) on the top and bottom surfaces. After positioning the specimen, the clearest vision of the specimen surface was checked through the $40 \times$ objective lens. A $300-g$ load was applied through the indenter for $15 \mathrm{~s}$. After complete indwelling of the indenter, the $40 \times$ objective lens was repositioned over the specimen surface to adjust the diameter two longitudinal lines to measure the length of D1 and D2 diagonal lines, then the D1 and D2 values were placed in the hardness tester through the digital panel, then after pressing the OK button, the tester measured the mean hardness value. Three readings were taken on the top and the bottom surface for each specimen.

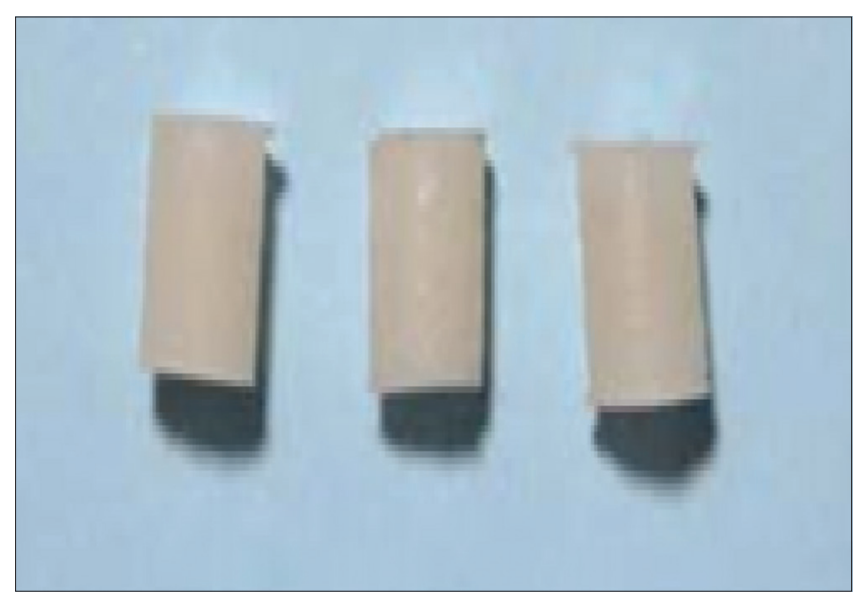

Figure 1: The cured specimens after removal of the mold assembly

\section{Statistical analysis}

Two-way ANOVA was done to compare the composite resin and curing energy effect on different variable studied. One-way ANOVA followed by pairwise Tukey's post hoc tests was performed to detect significance between each composite subgroups and t-test for subgroups. Statistical analysis was performed using Assistant 7.6 statistics software for Windows (Campina Grande, Paraiba state, Brazil). $p \leq 0.05$ was statistically significant in all tests.

\section{Results}

LED cured Tetric EvoCeram Bulk fill composite resin recorded higher bottom to top ratio than laser cured one and the difference in bottom to top ratio between both energies was statistically non-significant. LED cured Mosaic composite resin recorded higher bottom to top ratio than laser cured one. The difference in bottom to top ratio between light sources was statistically significant (Table 1 and Figure 2).

Table 1: Comparison of bottom to top (Mean values \pm SDs) between light sources and composite resins

\begin{tabular}{llll}
\hline Variables & Tetric EvoCeram Mean \pm SD & Mosaic Mean \pm SD & t-test \\
\hline Laser (10 S) & $92.01^{\mathrm{a}} \pm 7.48$ & $45.89^{\mathrm{b}} \pm 4.23$ & $<0.0001$ \\
Laser (15 S) & $94.32^{\mathrm{a}} \pm 5.11$ & $51.36^{\mathrm{b}} \pm 8.92$ & $<0.0001$ \\
Laser (20 S) & $91.97^{\mathrm{a}} \pm 5.05$ & $50.23^{\mathrm{b}} \pm 4.80$ & $<0.0001$ \\
LED (20 S) & $92.08^{\mathrm{a}} \pm 6.73$ & $90.85^{\mathrm{a}} \pm 9.90$ & 0.9818 \\
$\mathrm{p}$-value & 0.8792 & $<0.0001$ & \\
\hline Different superscript letter in the same column indicates statistically significant difference $(\mathrm{p}<0.05)$.
\end{tabular}




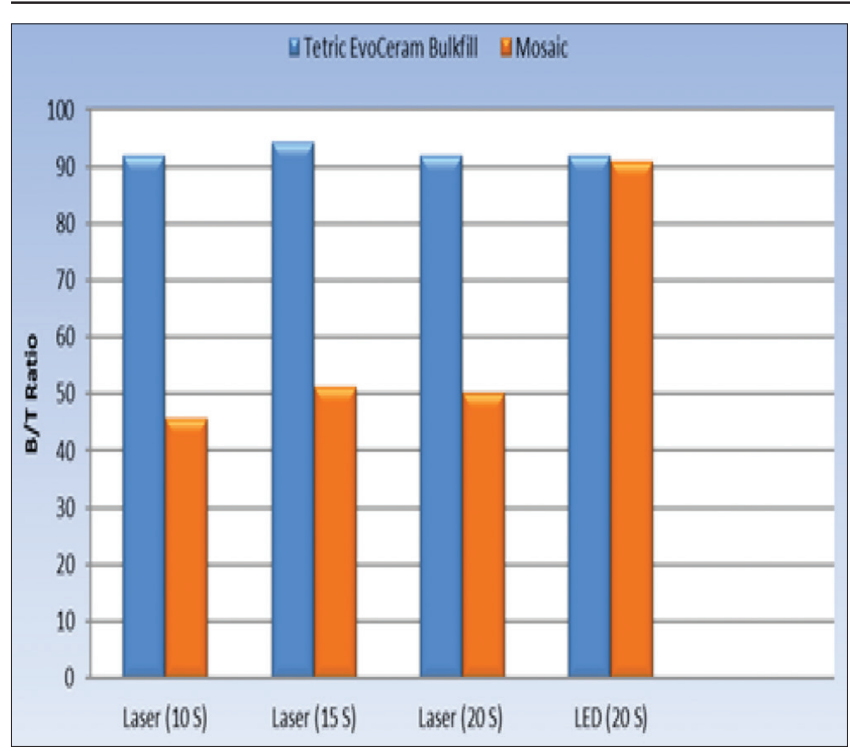

Figure 2: Column chart of the mean values of $B / T$ ratio for different light sources with composite resins

\section{Discussion}

During the application of composite resin restoration, the degree of polymerization has a great impact on the material. Therefore, new technologies have been developed to produce appropriate amount of light during curing which influences the physical and mechanical properties of the composite resin [11]. The type of curing light and curing mode has great impact on the quantity and quality of the composite resin polymerization [12]. LED light cure was proposed by Mills in 1995 to polymerize composite resins [13]. It emits light at specific wavelength within $400-\mathrm{nm}$ to $500-\mathrm{nm}$ photoabsorption range of camphorquinone (CQ) [14]. Newly developed types of photoinitiators such as diphenyl (2,4,6-trimethylbenzoyl) phosphine oxide (TPO) and Ivocerin absorb light most effectively within lower wavelength range and act as substitute for the $C Q$ to reduce the yellow coloration [15]. Therefore, manufacturers started to use these photoinitiators to produce restorations of high color value with high reactive initiators that increase the depth of curing [7]. LED light cure, poly wave that emit multiple wavelengths was introduced, which was used in this study (BlueLEX LD-105, Monitex, Taiwan) has the advantage of curing composite resins that contain more than one photoinitiator with different light absorption spectra [16]. Laser system (SIROLaser Blue- SIRONA, Germany) was the first dental diode laser having blue, infrared, and red diode that contains Blue diode laser and produces $445 \mathrm{~nm}$ wavelength. Surface microhardness of composite resins has been used to evaluate the efficiency of the light cure unit and to evaluate the extent of polymerization indirectly [17]. The obtained results showed that Vickers microhardness test of Tetric EvoCeram composite resin group cured the top surface for $10 \mathrm{~s}$ with laser cured subgroup recorded the highest mean value followed by $20 \mathrm{~s}$ LED cured subgroup followed by $15 \mathrm{~s}$ laser cured subgroup while the lowest subgroup was cured for $20 \mathrm{~s}$ with laser. Furthermore, the Vickers microhardness of Mosaic composite resin group when cured the top surface for $15 \mathrm{~s}$ laser cured subgroup recorded the highest mean value of Vickers microhardness followed by 20 s LED cured subgroup followed by $10 \mathrm{~s}$ laser cured subgroup and the lowest subgroup was the $20 \mathrm{~s}$ laser cured. The results agree with Ceballos et al. [18], who stated that the interactions between light curing source and exposure time and between light curing unit and depth significantly influence microhardness results. High microhardness values may be related to the type and concentration of photoinitiators [19] and to the materials composition. There was a positive correlation between composite resin microhardness and the inorganic particle content, as increasing the filler content will lead to higher microhardness [20]. Dickens et al. [21] stated that the hardness of the composite resin gets affected by the crosslinking and the network formation that developed during the setting. Network formation occurs after an initial stage of polymer chain propagation. Tetric EvoCeram composite resin has different types of photoinitiators such as camphorquinone and Ivocerin and different filler particle size and amount $(81 \%$ wt., $61 \%$ vol) [22] which increase the ray light scattering [23]. Some of the small wavelength photons will reach the bottom layers of the composite resin and the other photoinitiators will have to be activated by the less efficient longer wavelengths of light. This may explain why some researchers found that the microhardness of the bottom layer cured by camphorquinone based materials was significantly greater than TPO-based materials that were cured using a light cure unit that delivered the light output in the range of 450$500 \mathrm{~nm}$ [24]. On the other hand, Dionysopoulos et al. [25] found no significant differences in microhardness between different types of the composite resins when tested. This could be related to the difference in the composition of the composite resin as they used nanocomposites and, in this study, we used bulkfill nanohybrid and universal nanohybrid composite resins in addition to the difference in the tested methodology. Aguiar et al. [26] in his study showed an improvement of hardness means with an increase of the light curing time, mainly on the bottom layer. The results of this study showed that regardless to curing energies it was found that Tetric EvoCeram resin composite resin recorded statistically significant higher bottom to top ratio than Mosaic composite resin. The results agreed with Hubbezuglo et al. [8], who stated that regardless of the light curing unit used, bottom surface hardness values were lower than those of the top surface of all the materials tested. This could be 
related to the reduction in the light intensity as it passes through the bulk composite resin which results in low absorption and scattering of light by the fillers and matrix [27] which leads to difference between the top and bottom layers hardness of different materials with different light curing sources [8]. This was agreed with our results as laser curing energy did not improve the hardness of the composite at $4 \mathrm{~mm}$ thickness of Mosaic in relation to the hardness values of bottom layer for Tetric EvoCeram resin composite. Another interpretation of this result is related to the composition of the materials, which influences the translucency, and consequently the energy density that reaches the deep layers of the materials. Microhardness of composite resin material does not only reflect the extent of polymerization, but other factors as well such as filler content Tetric Evoceram fillers are Barium glass, ytterbium trifluoride, mixed oxide and prepolymer and Mosaic fillers are Ceramic zirconia silica glass and filler size (Tetric EvoCeram fillers size: $40 \mathrm{~nm}-3,000 \mathrm{~nm}$, mean size: $550 \mathrm{~nm}$ and Mosaic fillers size: $0.02 \mathrm{um}$ ) that affects microhardness results [28]. It depends also on other factors, such as the organic matrix composition (Tetric EvoCeram organic matrix: Bis-GMA, Bis-EMA, UDMA [22] and Mosaic organic matrix: Bis-GMA, PEGDMA, TEGDMA) [28], [29] as the polymerization level varies according to the amount of monomers and oligomonomers present in the composite resins [20]. In addition, young's modulus of elasticity and viscosity plays a major role in the microhardness results. The composite resin viscosity is correlated with the type of resin matrix. Bis-GMA as the most viscous one is also least flexible, while UDMA and TEGDMA are least viscous [22]. The results showed that LED cured Tetric EvoCeram composite resin recorded higher $\mathrm{B} / \mathrm{T}$ ratio than laser cured one. The difference in $\mathrm{B} / \mathrm{T}$ ratio between both energies was statistically non-significant. Consequently, regarding the type of composite laser curing light device cured photoactivated Tetric EvoCeram dental composite materials and provided a hardness value as efficient as conventional LED light curing devices but with shorter time. For Mosaic resin composite it was noted that, LED cured Mosaic composite resin recorded higher $\mathrm{B} / \mathrm{T}$ ratio than laser cured one. This could be related to different factors which affects microhardness results such as the power of the light source, the quality of the light source, the distance between the light end and the composite surface, the layer thickness of the applied composite, the color of the composite and the composition of the organo-inorganic structure in the composite vary depending on the composition [10]. Long-time exposure to laser in the continuous mood may leads to heat generation on the outermost layer of the composite. Heat transmission to the materials may result in reduction in the hardness as the heat increase the monomer mobility by decreasing the cross liking and change the filler distribution on the outer top layer facing the laser source as agreed with Harrington and
Wilson [30] and Manhart et al. [31] Therefore, proper selection of the light curing unit and an adequate time for photopolymerization will result in satisfactory composite resin especially in deep cavity preparations [26].

\section{Conclusion}

SIROLaser Blue laser device increases the degree of polymerization and achieves better curing of composite resins than LED but the high cost and technique sensitivity result in their limited use.

\section{Recommendation}

Different types of curing systems are present in the dental practice. The use of SIROLaser Blue laser to photopolymerize composite resin will offers proper polymerization properties.

\section{Declarations}

\section{Availability of data and materials}

The datasets used and/or analyzed during the current study are available from the corresponding author on reasonable request.

\section{Competing Interests}

The authors declare that they have no competing interests.

\section{Funding}

Self-funded. This research did not receive any financial support.

\section{Authors' Contributions}

EA designed the study and performed the experiments. MA participated in data collection, revised 
the Background, Discussion, and Conclusion sections. All authors read and approved the final manuscript.

\section{References}

1. Bahbishi N, Mzain W, Badeeb B, Nassar H. Color stability and micro-hardness of bulk-fill composite materials after exposure to common beverages. Materials. 2020;13(3):787. https://doi. org/10.3390/ma13030787

PMid:32050415

2. Segalin AS, Fernandez D, Oliveria B, Loguercio A, Reis A. Marginal adaptation, and hardness of resin composite restorations activated with four energies. J Esthet Restor Dent. 2005;17(5):3030-10; discussion 311. https://doi. org/10.1111/j.1708-8240.2005.tb00135.x

PMid:16225795

3. AISagob E, Bardwell D, Ali A, Khayat S, Stark P. Comparison of microleakage between bulk-fill flowable and nanofilled resinbased composites. Interv Med Appl Sci. 2018;10(2):102-9. https://doi.org/10.1556/1646.10.2018.07

PMid:30363354

4. de Campos EA, Ardu S, Lefever D, Jasse F, Bortolotto T, Krejci I. Marginal adaptation of class II cavities restored with bulk-fill composites. J Dent. 2014;42(5):575-81. https://doi. org/10.1016/j.jdent.2014.02.007

PMid:24561041

5. Zorzina R, Maiera E, Harrea S, Feyb S, Bellia R, Lohbauera U, et al. Bulk-fill resin composites: Polymerization properties and extended light curing. Dent Mater. 2015;31(3):293-301. https:// doi.org/10.1016/j.dental.2014.12.010

PMid:25582061

6. Antonson S, Antonson D, Hardigan P. Should my new curing light be an LED? Oper Dent. 2008;33(4):400-7. https://doi. org/10.2341/07-103

PMid: 18666497

7. Rueggeberg F, Giannini M, Arrais C, Price R. Light curing in dentistry and clinical implications: A literature review. Braz Oral Res. 2017;28(31 Suppl 1):e61. https://doi.org/10.1590/18073107bor-2017.vol31.0061

PMid:28902241

8. Hubbezoğlu I, Bolayir G, Doga A, Ozer A. Microhardness evaluation of resin composites polymerized by three different light sources. Dent Mater J. 2007;26(6):845-53. https://doi. org/10.4012/dmj.26.845

PMid: 18203490

9. Wazir N, Choudhary D, Rathore H. An in vitro study to evaluate depth of cure of bulk-fill composites a comparative study. Int J Res Health Allied Sci. 2020;2(6):59-61. https://doi. org/10.2341/06-163

10. Cetin A, Hataysal A, Kaplan T, Botsali M. Depth of cure and microhardness of a new composite vs. bulk-fill composites. J Res in Med Dent Sci. 2019;7(5):53-9.

11. Rode K, Kawano $\mathrm{Y}$, Turbino M. Evaluation of curing light distance on resin composite microhardness and polymerization. Oper Dent. 2007;32(6):571-8.

PMid: 18051007

12. Malhotra N, Mala K. Light curing considerations for resin based composite materials: A review part I. Compend Contin Educ Dent. 2010;31(7):498-506; quiz 506, 508.

PMid:20879203
13. Dun W, Bush A. A comparison of polymerization by light-emitting diode and halogen-based light-curing units. J Am Dent Assoc. 2002;133(3):335-41.

PMid:11934189

14. Christensen GJ. The curing light dilemma. J Am Dent Assoc. 2002;133(6):761-3.

PMid:12083654

15. Alvim $\mathrm{H}$, Alecio A, Vasconcellos $\mathrm{W}$, Furlan $\mathrm{M}$, de Oliveira J, Saad J. Analysis of camphorquinone in composite resins as a function of shade. Dent Mater. 2007;23(10):1245-9. https://doi. org/10.1016/j.dental.2006.11.002 PMid: 17204320

16. Maktabi H, Balhaddad A, Alkhubaizi Q, Strassler H, Melo M. Factors influencing success of radiant exposure in light curing posterior dental composite in the clinical setting. Am J Den.2018;31(6):320-8. PMid:30658380

17. Alrahlah A, Silikas N, Watts D. Post-cure depth of cure of bulk fill dental resin-composites. Dent Mater. 2014;30(2):149-54. https://doi.org/10.1016/j.dental.2013.10.011 PMid:24268044

18. Ceballos L, Fuentes M, Tafalla H, Martínez A, Flores J, Rodríguez J. Curing effectiveness of resin composites at different exposure times using LED and halogen units. Med Oral Patol Oral Cir Bucal. 2009;14(1):51-6.

PMid:19114957

19. Knezevic A, Ristic M, Demoli N, Tarle Z, Music S, Negovetic V. Composite photopolymerization with diode laser. Oper Dent. 2007;32(3):279-84. https://doi.org/10.2341/06-79

PMid: 17555180

20. Nogueira J, Borsatto M, de Souza-Zaron W, Ramos R, PalmaDibb R. Microhardness of composite resins at different depths varying the post-irradiationtime. JAppl OralSci. 2007;15(4):305-9. https://doi.org/10.1590/s1678-77572007000400012 PMid:19089149

21. Dickens S, Stansbury J, Choi K, Floyd C. Photopolymerization kinetics of methacrylate dental resins. Macromolecules. 2003;36(16):6043-53. https://doi.org/10.1021/ma021675k

22. Kelić K, Matić S, Marović D, Klarić E, Tarle Z. Microhardness of bulk-fill composite materials. Acta Clin Croat. 2016;55(4):607-14. https://doi.org/10.20471/acc.2016.55.04.11

PMid:29117652

23. Masotti A, Onófrio Á, Conceição E, Spohr A. UV-vis spectrophotometric direct transmittance analysis of composite resins. Dent Mater. 2007;23(6):724-30. https://doi.org/10.1016/j. dental.2006.06.020

PMid:16914194

24. Leprince J, Hadis M, Shortall A, Ferracane J, Devaux J, Leloup G, et al. Photoinitiator type and applicability of exposure reciprocity law in filled and unfilled photoactive resins. Dent Mater. 2011;27(2):157-64. https://doi.org/10.1016/j.dental.2010.09.011 PMid:21067803

25. Dionysopoulos D, Papadopoulos C, KoliniotouKoumpia E. Effect of temperature, curing time, and filler composition on surface microhardness of composite resins. J Conserv Dent. 2015;18(2):114-8. https://doi. org/10.4103/0972-0707.153071 PMid:25829688

26. Aguiar F, Braceiro A, Lima D, Ambrosano G, Lovadino J. Effect of light curing modes and light curing time on the microhardness of a hybrid composite resin. J Contemp Dent Pract. 2007;8(6):18. https://doi.org/10.5005/jcdp-8-6-1 PMid:17846665

27. Neo BJ, Soh MS, Teo JW, Yap AU. Effectiveness of composite 
cure associated with different light-curing regimes. Oper Dent. 2005;30:671-5.

28. Dionysopoulos D, Tolidis K, Gerasimou P. The effect of composition, temperature and post-irradiation curing of bulk fill resin composites on polymerization efficiency. Mater Res. 2016;19(2):466-73. https://doi. org/10.1590/1980-5373-mr-2015-0614

29. Soares $P$, Peres $T$, Wobido A, Machado A. Composite resin in the last 10 years literature review. Part 1: Chemical composition. J Clin Dent Res. 2019;16(1):45-56.
30. Harrington E, Wilson $\mathrm{H}$. Determination of radiation energy emitted by light activation units. J Oral Rehabil. 1995;22(5):37785. https://doi.org/10.1111/j.1365-2842.1995.tb00788.x

PMid:7616349

31. Manhart J, Kunzelmann K, Chen H, Hickel R. Mechanical properties, and wear behaviour of light-cured packable composite resins. Dent Mater. 2000;16(1):33-40. https://doi. org/10.1016/s0109-5641(99)00082-2

PMid:11203521 